\title{
Everyday Aids and Appliances
}

\section{CHOOSING EASY CHAIRS FOR THE DISABLED}

Although good seating can contribute to the well being of the elderly and those with arthritis, who may spend long periods sitting, these people often have problems with their chairs.

When a person rises from a chair the forces in the knee joint are up to seven times body weight, a large force for painful joints to bear. Patients with muscle wasting and stiffness may have difficulty in rising; so may those with rheumatoid hands who experience pain when pushing or gripping and those whose shoulders cannot take the brunt of weight transfer. Obesity frequently supervenes because of inactivity, thereby compounding the problem of rising.

\section{Seat height}

The higher the seat the easier it is to rise from. The joint and muscle forces used in lifting from a high seat are $20 \%$ less than those required in rising from a low one. If the seat is too high, however, the feet may dangle, causing fatigue and discomfort, and the seat may indent the back of the thighs near the knee.

\section{Seat angle}

A horizontal seat with a sloping back rest is uncomfortable and causes the patient to slide forward. When the seat slope is too great rising from the chair is difficult. The seat should therefore slope gently backwards. An angle of $6^{\circ}$ is a good compromise.

\section{Seat construction}

If the chair has a hard support rail at the front underneath the cushion the edge may dig into the thighs as the cushion sags, causing pain and restricting circulation. "Hammocking" of the seat often causes shear stresses on the buttocks, resulting in pain in the hips and possible pressure sores.

The cushion or seat should be made of good quality materials. Foams quickly lose their resilience, and the sitter then feels the hard bottom of the seat. The resultant high loads under the ischial tuberosities can lead to pressure sores. Foams and coverings should allow a flow of air through the seat to reduce the effects of perspiration and localised overheating of the skin. Open cell foams are therefore preferable to the closed cell variety.

\section{Covers}

Incontinent patients will be more comfortable if the seat covering can absorb moisture. Removable sheepskin covers are suitable as these feel soft and warm, can absorb a large amount of moisture yet still feel dry, and are easily washed. They also allow good ventilation, reducing localised overheating of the skin, and help absorb perspiration. Covers should be hard wearing, and the material should be neither too rough (which would restrict movement) nor too slippery. Sewn in buttons on the cushion or backrest can dig into the flesh and should be avoided.

\section{Backrest}

The human back is not straight but curved, with a cervical lordosis, thoracic kyphosis, and lumbar lordosis. The ideal backrest should be shaped accordingly, obviating the need for extra cushions, which may slip, become squashed, or be awkward to adjust.

If the backrest is too upright the muscles in the back tense to stop the trunk from falling forward, so relaxation is difficult. If it is inclined too greatly the body tends to slide down the chair and getting up is difficult. The backrest should slope gently backward and be high enough to support the full length of the back.

The head should also be supported. A protruding headrest should, however, be avoided as it pushes the head forward, forcing the neck muscles to restrain the head; this results in neck pain. Although wings on a chair are popular, care must be taken that they do not socially isolate the sitter.

\section{Armrests}

Armrests which are too low inhibit rising. Those which are too high cause people to hunch their shoulders when resting their arms on them. Armrests of the correct height greatly assist rising from the

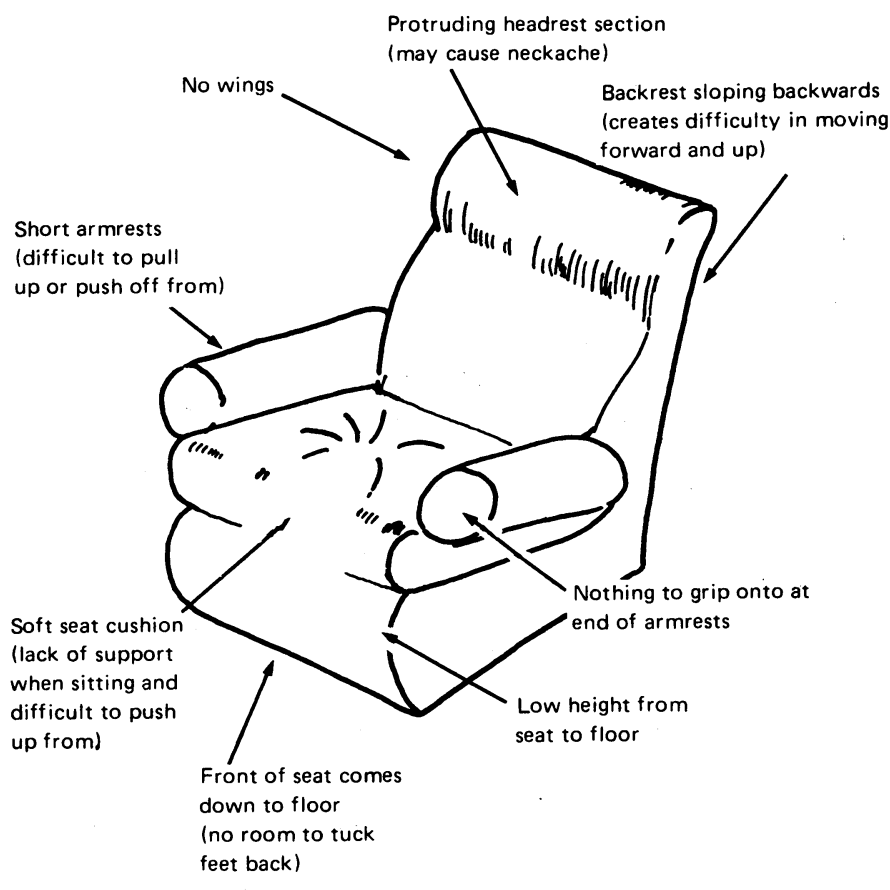

A poor chair for a patient with arthritis. 


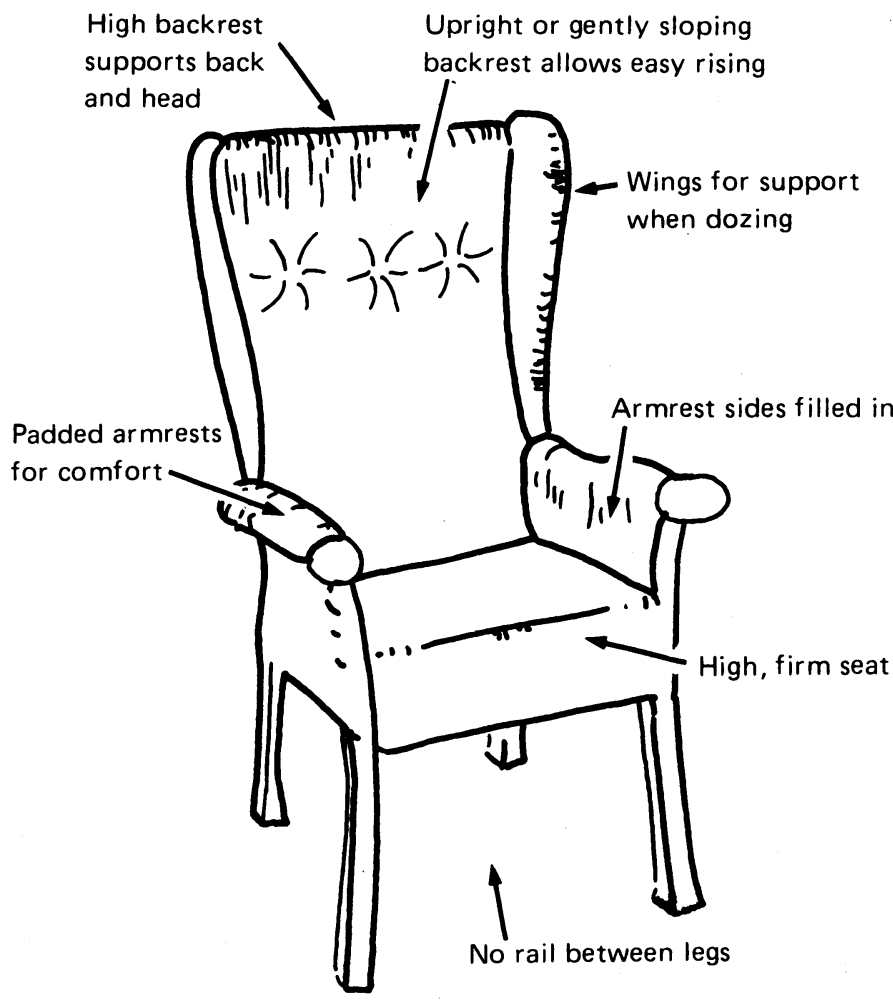

A good chair for a patient with arthritis.

seated position. Biomechanical analysis has shown them to be of greater value than a high seat in minimising the joint and muscle forces used when rising.

Also, handgrips greatly assist in rising, especially initially. Large rounded ends will be less painful to grip for those with arthritic hands. Longer armrests facilitate rising more than short ones. For added comfort armrests should be partially padded. Filled in sides help retain warmth, exclude draughts, and prevent items such as newspapers, knitting, etc from falling from the chair. Filled in sides also retain fallen cigarettes, however, so a chair made from fire resistant materials is desirable.

\section{General construction}

Strength, stability, and safety are of great importance for the arthritic easy chair user. A chair which is high and has splayed legs has increased stability. The chair should be constructed so that the sitter can tuck his feet back under the seat: rising is easier when the body's centre of gravity falls over the ankles at an earlier point in the rising action.

Some people use their furniture as a support to aid walking within their home; others flop into their chairs heavily. Chairs should therefore be sturdy and well built.

The disabled are more at risk in a fire than the ambulant. Although manufacturers may argue against fireproofing of seating materials because of the extra cost, the Leeds survey ${ }^{1}$ showed that arthritics consider this to be quite a high priority when choosing a chair.

Castors may help in moving the chair, and larger castors may be better than smaller ones, which might sink into carpets. For those who flop into their chairs only the front legs should be fitted with castors.

Although function is paramount, patients should be pleased with the appearance of their chairs; otherwise they may not use them. The chair should fit in with existing furniture in size, design, and colour so that the disabled person does not feel unnecessarily different.

Attachments such as ashtrays, tables, crutch and stick holders, side pockets and footrests (for those with fixed flexion deformities) can be of great benefit for many disabled people.

\section{Mechanised chairs}

Patients who experience great difficulty in rising, even from a well designed chair, may benefit from a spring assisted seat (to be placed in their own easy chair), or a spring assisted chair. This may, however, be a compromise: some patients have commented that although a spring assisted seat helped them to rise, it was hard and uncomfortable to sit on. A motorised chair which lifts the patient into a standing position, or raises him to a higher seat level, may be the answer for those for whom rising from a chair is a severe problem. It is advisable to seek professional advice about the suitability and safety of these devices for a specific patient.

\section{Further advice}

Professional advice may be obtained from the local disabled living centre. An appointment is usually required to visit the centre, where a large number of suitable chairs (and other aids) can be tried and their merits discussed. Further information can be obtained from the Disabled Living Foundation, 380-384 Harrow Road, London W9 2HU (telephone 012896111 ).

A pamphlet entitled Are you sitting comfortably? describes what to look for when choosing an easy chair. This publication is available from the Arthritis and Rheumatism Council, 41 Eagle Street, London WC1R 4AR.

A selection of easy chairs is available through social services departments. But it is such a limited selection that a patient may compromise by choosing a chair not entirely suitable for his needs, and which can be detrimental to him. It is recommended that the patient should contact his local community occupational therapist for guidance.

Finally, the best advice anyone can offer to someone choosing an easy chair is "try it before you buy it, preferably for as long as you can."

\section{Reference}

1 Ellis MI, Munton JS, Chamberlain MA. Seating for the elderly and arthritic. London: DHSS, 1983.

What reasoning lies behind the licensing authority's decision to allow a person with epilepsy who is free from fits for three years to have a driving licence to drive a car, yet not allowing someone who has had only one fit after the age of 5 years to obtain a public service vehicle or heavy goods vehicle licence?

The Heavy Goods Vehicles (Drivers' Licences) (Amendments) Regulations 1982 bars a person from holding a licence to drive public service vehicles (PSV) and heavy goods vehicles (HGV) if he or she (a) has suffered an epileptic attack since the age of 5 or $(b)$ has any disease likely to cause a danger to the public if he or she drives a public service vehicle or heavy goods vehicle. These drivers spend longer hours driving than most car drivers and so are more likely to be involved in events that cause an accident. The risk of death or serious injury to other road users in collisions with heavy goods vehicles is high because of their mass and lower braking capacity. Drivers of HGVs are involved in $\mathbf{8 0} \%$ more fatal and serious injury accidents per million miles driven than car drivers. Public service vehicles, particularly buses, present a hazard because they have to stop repeatedly where people are waiting to board them and the consequences of loss of control by the driver are very serious. Further information is contained in Medical Aspects of Fitness to Drive. ${ }^{1}$ - A B RAFFLE, formerly chief medical officer, London Transport Executive.

1 Medical Commission on Accident Prevention. Epilepsy. In: Raffle A, ed. Medical aspects of fimess to drive. London: Medical Commission on Accident Prevention, 1985. 